\title{
Streptococcus pneumoniae fructose-1,6-bisphosphate aldolase, a protein vaccine candidate, elicits Th1/Th2/Th17-type cytokine responses in mice
}

\author{
SHIRIN ELHAIK GOLDMAN ${ }^{1,2^{*}}$, SHAHAR DOTAN $^{3 *}$, AMIR TALIAS $^{1,2}$, AMIT LILO $^{1,2}$, SHALHEVET AZRIEL $^{1,2}$, \\ ITAY MALKA $^{1,2}$, MAXIM PORTNOI $^{1,2}$, ARIEL OHAYON ${ }^{1,2}$, DANIEL KAFKA ${ }^{1,2}$, RONALD ELLIS ${ }^{3}$, \\ MOSHE ELKABETS ${ }^{2}$, ANGEL PORGADOR ${ }^{2}$, DITZA LEVIN ${ }^{4}$, ROSA AZHARI $^{4}$, EDWIN SWIATLO ${ }^{5}$, \\ EDUARD LING ${ }^{1,2}$, GALIA FELDMAN $^{1,2}$, MICHAEL TAL $^{3}$, RON DAGAN $^{1}$ and YAFFA MIZRACHI NEBENZAHL ${ }^{1,2}$ \\ ${ }^{1}$ Pediatric Infectious Disease Unit, Soroka University Medical Center, Beer-Sheva 84100; ${ }^{2}$ The Shraga Segal \\ Department of Microbiology, Immunology and Genetics, Faculty of Health Sciences, Ben-Gurion University of the Negev, \\ Beer-Sheva 84105; ${ }^{3}$ NasVax/Protea Vaccine Technologies Ltd., Kiryat Weizmann, Science Park, Ness Ziona 74140; \\ ${ }^{4}$ Prof. Ephraim Katzir Department of Biotechnology Engineering, ORT Braude College, Karmiel 21982, Israel; \\ ${ }^{5}$ Division of Infectious Diseases, University of Mississippi Medical Center, Jackson, MS 39216, USA
}

Received November 30, 2015; Accepted February 8, 2016

DOI: $10.3892 /$ ijmm.2016.2512

\begin{abstract}
Streptococcus pneumoniae (S. pneumoniae) is a major pathogen worldwide. The currently available polysaccharide-based vaccines significantly reduce morbidity and mortality. However, the inherent disadvantages of the currently available polysaccharide-based vaccines have motivated the search for other bacterial immunogens capable of eliciting a protective immune response against $S$. pneumoniae. Fructose1,6-bisphosphate aldolase (FBA) is a glycolytic enzyme, which was found to localize to the bacterial surface, where it functions as an adhesin. Previously, immunizing mice with recombinant FBA (rFBA) in the presence of alum elicited a protective immune response against a lethal challenge with $S$.pneumoniae. Thus, the aim of the present study was to determine the cytokine responses that are indicative of protective immunity following immunization with rFBA. The protective effects against pneumococcal challenge in mice immunized with rFBA with complete Freund's adjuvant (CFA) in the initial immunization and with incomplete Freund's adjuvant (IFA) in booster immunizations surpassed the protective effects observed following immunization with either rFBA + alum or pVAC ${ }^{f b a}$. $\mathrm{CD}^{+} \mathrm{T}$-cells obtained from the rFBA/CFA/IFA/IFA-immunized mice co-cultured with rFBA-
\end{abstract}

Correspondence to: Professor Yaffa Mizrachi Nebenzahl, The Shraga Segal Department of Microbiology, Immunology and Genetics, Faculty of Health Sciences, Ben-Gurion University of the Negev, Rager Avenue, Beer-Sheva 84105, Israel

E-mail: ymizr@bgu.ac.il

*Contributed equally

Key words: Streptococcus pneumoniae, fructose-1,6-bisphosphate aldolase, vaccine, cytokines pulsed antigen-presenting cells (APCs), exhibited a significantly greater proliferative ability than $\mathrm{CD}^{+} \mathrm{T}$-cells obtained from the adjuvant-immunized mice co-cultured with rFBA-pulsed APCs. The levels of the Th1-type cytokines, interferon (IFN)- $\gamma$, interleukin (IL)-2, tumor necrosis factor (TNF)- $\alpha$ and IL-12, the Th2-type cytokines, IL-4, IL-5 and IL-10, and the Th17-type cytokine, IL-17A, significantly increased within $72 \mathrm{~h}$ of the initiation of co-culture with $\mathrm{CD}^{+}{ }^{+} \mathrm{T}$-cells obtained from the rFBA-immunized mice, in comparison with the co-cultures with $\mathrm{CD}^{+}$T-cells obtained from the adjuvant-immunized mice. Immunizing mice with $\mathrm{rFBA}$ resulted in an $\mathrm{IgG1} / \mathrm{IgG} 2$ ratio of 41, indicating a Th2 response with substantial Th1 involvement. In addition, rabbit and mouse anti-rFBA antisera significantly protected the mice against a lethal $S$. pneumoniae challenge in comparison with preimmune sera. Our results emphasize the mixed involvement of the Th1, Th2 and Th17 arms of the immune system in response to immunization with pneumococcal rFBA, a potential vaccine candidate.

\section{Introduction}

Streptococcus pneumoniae (S. pneumoniae), which is a major pathogen found in infants, the elderly and the immunocompromised, is responsible for more than one third of the two million global annual deaths of children following acute respiratory infections. The currently available polysaccharidebased vaccines provide an antibody-dependent protection (1) and significantly reduce morbidity and mortality (2). The pneumococcal polysaccharide vaccine Pneumovax 23 (PPV23), consists of 23 pneumococcal polysaccharides from the most common disease-causing serotypes. However, PPV23 does not provide long-lasting protection and is ineffective in infants. The polysaccharide-protein conjugate vaccine, which includes up to 13 pneumococcal polysaccharides, elicits long-term protection, but provides only a limited coverage, as the elicited immune 
response is serotype-specific (1). These inherent disadvantages have motivated the search for other bacterial immunogens, such as bacterial proteins, capable of eliciting a protective immune response against $S$. pneumoniae $(3,4)$.

Probably the most important concern today in the field of vaccine development is our inadequate understanding (3) of how to induce a specific, potent and durable protective immune response (5). The majority of available vaccines confer protection through antibodies, the levels of which are defined as correlates of protection. Although the correlates of immune response to $S$. pneumoniae proteins are emerging, studies have found that the protection elicited by carriage or immunization with whole-cell vaccines is $\mathrm{CD} 4^{+} \mathrm{T}$-cell dependent and antibody-independent $(6,7)$, and has been suggested to involve mainly the Th17 arm (8). However, other studies have shown that both the Th17 and the Th1 arms are necessary for the development of the protective immune response, whereas the Th2 response is negligible $(9,10)$.

A variety of proteins displayed on the cell wall of $S$. pneumoniae have been found to confer protection against pneumococcal infection. Some of these proteins are adhesins, e.g., choline binding protein $\mathrm{A}(\mathrm{CbpA})(11,12)$, pneumococcal choline binding protein A (PcpA) (13), pneumococcal histidine triad protein $\mathrm{D}(\mathrm{PhtD})(3)$, pneumococcal surface adhesin A (PsaA) (14) and pneumococcal serinerich repeat protein (PsrP) (15), while others are involved in various other bacterial functions e.g., pneumococcal surface protein A (PspA), which reduces complement deposition on the bacterium (16), protein required for cell wall separation of group B streptococcus ( $\mathrm{PcsB})$, which is involved in bacterial cell division; or serine/threonine protein kinase (StkP), which is involved in bacterial morphogenesis $(10,17)$.

Fructose-1,6-bisphosphate aldolase (FBA) is a glycolytic enzyme that is highly conserved (99\%) among $S$. pneumoniae strains. FBA has also been found to localize to the surface of different pathogens, including Gram-positive bacteria, Gram-negative bacteria and parasites (18-21). In S. pneumoniae, FBA surface localization was demonstrated by biochemical fractionation of the cell wall and by the flow cytometry of live bacteria immunostained with mouse antisera against recombinant (r)FBA $(22,23)$. FBA has also been shown to function as an adhesin in S. pneumoniae and in Neisseria meningitidis $(19,24)$. Furthermore, Flamingo cadherin receptor (FCR), a cell adhesion molecule, was found to be a $S$. pneumoniae FBA target receptor. Additionally, a peptide derived from FCR was found to inhibit $S$. pneumoniae adhesion in vitro and prevent disease development in vivo in a mouse model (24). It has been found that FBA elicits an age-dependent antigenicity in infants and that it is immunogenic in mice $(22,23)$. Finally, immunizing mice with rFBA in the presence of alum has been shown to elicit a protective immune response against a lethal challenge with $S$. pneumoniae (22). Thus, rFBA emerges as a promising vaccine candidate against $S$. pneumoniae.

Aluminum-based compounds are the major adjuvants used, to date, in human vaccination. Although they induce a good Th2 antibody response to the immunogen, they also inhibit humoral and cellular Th1 and Th17 responses. Alum salts are potent inhibitors of Toll-like receptor (TLR) agonist-induced interleukin (IL)-12 secretion, an effect that is mediated by alum-driven phosphoinositide (PI)3 kinase signaling. Moreover, alum salts have been shown to reduce the ability of the immune system to promote Th17 responses due to their effect on the production of IL-23 (25). Thus, we hypothesized that the protective effects elicited by alum salts are not unsurpassed.

In the present study, we explored the ability of rFBA to protect mice against an S. pneumoniae challenge and investigated the cytokine profiles elicited in mice immunized with rFBA. In addition, we evaluated the production of functional protective antibodies capable of protecting the host against an S. pneumoniae challenge.

\section{Materials and methods}

Reagents. Unless otherwise stated, all chemicals and biochemicals were of the highest purity available and were purchased from Sigma-Aldrich (St. Louis, MS, USA).

Bacterial strains and growth conditions. The encapsulated S. pneumoniae serotype 3 strain WU2 (25) was grown as previously described (26). Briefly, pneumococci were grown in Todd-Hewitt broth supplemented with $0.5 \%$ yeast extract (THY) or on blood agar plates.

Mice. Seven-week-old female BALB/cOlaHsd mice $(\mathrm{n}=121$; thereafter referred to as BALB/c mice; Harlan Laboratories, Rehovot, Israel) and 7-week-old CBA/CaHN-Btk ${ }^{\text {xid }}$ mice (CBA/N ${ }^{x i d}$; Jackson Laboratories, Bar Harbor, ME, USA) were used in this study. The experiments were performed at one of two locations: i) at the animal facility of Ben-Gurion University of the Negev, Beer-Sheva, Israel, in accordance with the guidelines and approval of its Institutional Animal Care and Use Committee (IACUC) (permit no. 53.08.08); or ii) at the University of Mississippi Medical Center, Jackson, MS, USA, in accordance with the guidelines and approval of the relevant IACUC (permit no. 00163).

In all the experiments, the mice were euthanized with $\mathrm{CO}_{2}$. In the survival experiments, the mice were monitored for fur appearance, social involvement, and their eating and drinking ability. Any mouse demonstrating an apparent illness, manifested by the appearance of bristled fur, social disengagement, or an inability to eat or drink, was euthanized with $\mathrm{CO}_{2}$.

Cloning, expression and purification of rFBA. HAT-tagged rFBA was cloned as previously described (22). To prevent any alterations in the immune profile, an untagged protein was cloned, purified and then used for examining the cytokine profile elicited by rFBA and for the analysis of the $\operatorname{IgG} 1 / \operatorname{IgG} 2 \mathrm{a}$ experiments. The gene from the locus tag SP_RS02975 that codes for FBA was amplified from the TIGR4 strain with the following primers: forward, 5'-ATGGGATCCATATGGCGA TTGTGTCTGCAGAA-3' (Nde1); and reverse, 5'-CATGGAGC TCGCTCAGCTTATTACGCTTTGCCTTCG-3' (Bpu11021). The amplified product was inserted into the $\mathrm{pET} 32 \mathrm{a}+$ vector and transformed in DH5 $\alpha$ UltraMAX ultracompetent Escherichia coli (E. coli) cells (Invitrogen, San Diego, CA, USA). Ampicillin-resistant transformants were selected and the vector was purified with a Qiagen HiSpeed Plasmid Maxi kit (Qiagen GmbH, Hilden, Germany). The pET32a+fba vector was transformed into E. coli host expression strain BL21(DE3) 
pLysS (Novagen, Jaffrey, NH, USA). The identity of the inserts was confirmed by sequencing. The protein was prepared under denaturing conditions and refolded under physiological conditions. rFBA was purified by anion-exchange and sizeexclusion chromatography. rFBA identity and purity were confirmed by matrix assisted laser desorption/ionization time-of-flight (MALDI-TOF) mass spectrometry. The lipopolysaccharide (LPS) concentration in the rFBA protein was $<8.9 \mathrm{EU} / \mathrm{mg}$.

Preparation of DNA vaccine. The gene SP_0605 coding for FBA was amplified from the TIGR4 strain and the following primers were used: forward, 5'-TCGGATCCATGGCAATCG TTTCAGCAGA-3' (BamH1); and reverse, 5'-TCGAATTCT GCTTTACCTTCTGAACCGA-3' (EcoR1). The amplified and BamH1- and EcoR1- (Takara Bio Inc., Otsu, Japan) digested DNA fragments were cloned into the pVAC plasmid, and the $\mathrm{pVAC}^{f b a}$ was transformed in DH5 $\alpha$ UltraMAX ultracompetent $E$. coli cells (both from Invitrogen). Zeocin ${ }^{\mathrm{TM}}$-resistant transformants were cultured and the vector was purified from the DH5 $\alpha$ cells with a Qiagen HiSpeed Plasmid Maxi kit (Qiagen $\mathrm{GmbH}$ ).

Immunization of mice with rFBA for the survival assay. The BALB/c mice were immunized in one of three ways: i) subcutaneously (SC) with $25 \mu \mathrm{g}$ of HAT-rFBA plus complete Freund's adjuvant (CFA) for the first immunization (day 0) and with incomplete Freund's adjuvant (IFA) in two subsequent booster immunizations (days 14 and 28; $\mathrm{n}=25$ ); ii) intramuscularly (IM) with $50 \mu \mathrm{g} \mathrm{pVAC}^{f b a}(\mathrm{n}=21)$; or iii) intraperitoneally (IP) with $25 \mu \mathrm{g}$ of HAT-rFBA and $75 \mu \mathrm{l}$ of the Imject Alum adjuvant (Pierce Biotechnology, Inc., Rockford, IL, USA; n=15) on days 0,14 and 28 . The control mice were immunized with the respective adjuvant (CFA/IFA/IFA n=34, pVAC, empty plasmid $\mathrm{n}=14$, Imject alum, $\mathrm{n}=6$ ). The results shown are composed of the three different experiments performed at different times; in each experiment, all three adjuvants were tested.

Immunization of mice with rFBA for cytokine profile determination. The BALB/c mice were immunized on day 0 with $10 \mu \mathrm{g}$ of untagged rFBA alone or with untagged rFBA plus CFA. Booster immunizations of rFBA alone or of rFBA with IFA were administered on days 7 and 21. The control mice were immunized with CFA/IFA alone. All mice were injected $\mathrm{SC}$ on both inner thighs, $25 \mu \mathrm{l} /$ thigh.

Inoculation of immunized mice. The immunized BALB/c mice were inoculated intranasally with a lethal dose of $10^{8} \mathrm{CFU}$ of WU2. Survival was monitored daily.

Preparation of antigen-presenting cells (APCs). The mononuclear cells obtained from the spleens of naïve BALB/c mice were treated as previously described (27). Briefly, they were treated with rat anti-mouse monoclonal anti-CD4 (GK1.5), anti-CD8 (YTS169) and anti-Thy1.2 (30-H-12) antibodies, followed by the addition of a low-toxicity rabbit serum, as a source of complement. The monoclonal antibodies and the hybridomas were kindly provided by Professor L. Eizenbach from the Weizmann Institute of Science, Rehovot, Israel. The cells were treated with mitomycin $\mathrm{C}$. The verification of CD4 and CD8 cell depletion and of the purity of the APCs was performed by flow cytometry.

Enrichment of $C D 4^{+}$T-cells by positive selection. $\mathrm{CD}^{+} \mathrm{T}$-cells from the inguinal lymph nodes, popliteal lymph nodes and from the spleen were obtained from the mice in all immunization groups. The mice were euthanized and the lymph nodes and spleens were mechanically disrupted. $\mathrm{CD} 4^{+} \mathrm{T}$-cells were enriched using magnetic beads conjugated to rat anti-mouse

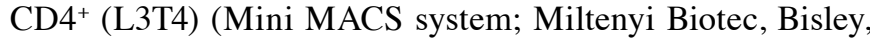
$\mathrm{UK})$. CD4 ${ }^{+}$enrichment (95\%) was verified by flow cytometry.

Bone marrow-derived dendritic cells (BMDCs). The BMDCs were generated from bone marrow cells obtained from BALB/c mice as described previously (28). Briefly, BMDCs were generated from bone marrow, which was obtained from BALB/c mice by flushing femoral cells with a 23-gauge needle with RPMI. Low-density mononuclear bone marrow cells were isolated using red blood cell lysing buffer (Sigma-Aldrich) and centrifuged. Cells $\left(5 \times 10^{6}\right)$ were cultured in $10-\mathrm{cm}$ tissue dishes with the fresh complete Iscove's Modified Dulbecco's Medium (cIMDM) with recombinant GM-CSF (100 ng/ml) or $20 \%$ lymphocyte conditioned medium (LCM), respectively. The medium was changed every 2-3 days and replaced with fresh medium supplemented with GM-CSF $(100 \mathrm{ng} / \mathrm{ml})$ or $20 \%$ LCM respectively. The following modification to the original protocol is: the cells were grown in a complete RPMI medium and were allowed to differentiate for 9 days prior to co-culture with $\mathrm{CD} 4^{+} \mathrm{T}$-cells.

Enrichment of $\mathrm{CD}^{+}$T-cells by negative selection. $\mathrm{CD} 4^{+} \mathrm{T}$-cells were harvested from the spleens and from the inguinal and popliteal lymph nodes of mice immunized with rFBA plus adjuvant, or with phosphate-buffered saline (PBS) plus adjuvant. The mononuclear cells were first separated with a standard Ficoll separation protocol. CD4 ${ }^{+}$T-cells were negatively selected using the EasySep $\mathrm{CD}^{+}{ }^{+} \mathrm{T}$-cell enrichment kit (StemCell Technologies, Inc., Vancouver, BC, Canada). The enrichment of CD4 ${ }^{+}$T-cells $\left(87-90 \% \mathrm{CD}^{+}\right.$cells out of 23,609 events) was verified by flow cytometry.

Antibodies used for flow cytometry. In the present study, phycoerythrin (PE)-conjugated rat anti-mouse CD11c, fluorescein isothiocyanate (FITC)-conjugated rat anti-mouse B220, FITCconjugated anti-mouse CD11b and allophycocyanin-conjugated rat anti-mouse major histocompatibility complex (MHC II) (IAbdq, I-Edk), all purchased from Pharmingen (San Diego, CA, USA), constituted the antibodies used for the purity verification of the APCs. The depletion of $\mathrm{CD}^{+}$and of $\mathrm{CD}^{+} \mathrm{T}$-cells was verified with a FITC-conjugated rat anti-mouse CD4 and rat anti-mouse CD8 (YTS169) respectively, detected using a FITC-conjugated AffiniPure F(ab')2 fragment of mouse antirat IgG $(\mathrm{H}+\mathrm{L})$ (Jackson ImmunoResearch Laboratories, Inc., West Grove, PA, USA). The negative selection of $\mathrm{CD}^{+}$T-cells was verified using PE-conjugated rat anti-mouse CD4 and allophycocyanin-conjugated rat anti-mouse CD45 (eBioscience, San Diego, CA, USA). Stained cells were analyzed using either FACSCalibur or FACS Canto II (Becton-Dickinson, Mountain View, CA). The data were then analyzed using CELLQuest ${ }^{\mathrm{TM}}$ software (version 3.3; BD Biosciences, San Jose, CA, USA) or 
with FlowJo software (version 6.3.4; Tree Star Inc., Ashland, OR, USA). Fluorescence data were acquired using logarithmic amplification and the reported fluorescence intensity units represent conversion of channel values according to the logarithmic scale.

\section{In vitro stimulation of $C D 4^{+} T$-cells}

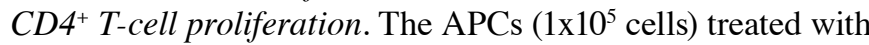
mitomycin $\mathrm{C}$ were incubated with increasing concentrations of rFBA $(0-2 \mu \mathrm{g} / \mathrm{ml})$ for $30 \mathrm{~min}$ in RPMI supplemented with $10 \%$ heat-inactivated fetal calf serum (FCS). An enriched $\mathrm{CD}^{+} \mathrm{T}$-cell population was added to the rFBA-pulsed APCs (1:1) and incubated for $72 \mathrm{~h}$ at $37^{\circ} \mathrm{C}$. CD4 ${ }^{+}$T-cell proliferation was evaluated as previously described (27), with a slight modification, namely, the extent of proliferation was determined using the BrdU ELISA kit (Hoffman-La Roche, Nutley, NJ, USA) according to the manufacturer's instructions. In these experiments we used 3 mice in each group and the results are a summary of 2 independent experiments, thus, 12 mice were used to perform these experiments.

Cytokine secretion. BMDCs, differentiated as previously described (28), were matured on cRPMI (penicillin $100 \mathrm{U} / \mathrm{ml}$, streptomycin $100 \mu \mathrm{g} / \mathrm{ml}$, L-glutamine $2 \mathrm{mM}$, 2-mercaptoethanol $50 \mu \mathrm{m}$, FCS $10 \%$ ) containing $100 \mathrm{ng} / \mathrm{ml}$ LPS for $5 \mathrm{~h}$, and then pulsed with $10 \mathrm{ng} / \mathrm{ml} \mathrm{rFBA}$ for $24 \mathrm{~h}$ at $37^{\circ} \mathrm{C}$. The enriched $\mathrm{CD}^{+} \mathrm{T}$-cells, obtained from rFBA-immunized and PBS-immunized mice $\left(5 \times 10^{6}\right.$ cells), were co-cultured with 10-day-stimulated BMDCs $\left(1 \times 10^{6}\right.$ cells $)$ in triplicate wells. The supernatants were collected at the denoted times and were frozen at $-20^{\circ} \mathrm{C}$ for later analysis. The cytokine concentrations were determined with a Bio-Plex cytokine (11-plex) assay (Bio-Rad Laboratories, Berkeley, CA, USA) according to the manufacturer's instructions. In addition, the concentration of interferon- $\gamma($ IFN- $\gamma)$ was determined using an ELISA kit (Becton-Dickinson) according to the instructions provided by the manufacturer. In these experiments we used 3 mice in each group and the results are a summary of 3 independent experiments, thus, 18 mice were used to perform these experiments.

Quantitative analysis of IgG1 and IgG2a by ELISA. Two weeks after the final immunization, the BALB/c mice were euthanized and individually bled from the heart. ELISA was carried out in a 96-well plate coated with rFBA. Individual samples of mouse serum were added to the rFBA-coated plates. The concentrations of anti-rFBA mouse IgG1 and anti-mouse $\mathrm{IgG} 2 \mathrm{a}$ were determined with biotin-conjugated goat anti-mouse $\operatorname{IgG} 1$ and biotin-conjugated goat anti-mouse IgG2a (Southern Biotechnology Associates, Birmingham, AL, USA), respectively, together with streptavidin-horseradish peroxide (HRP; Jackson ImmunoResearch Laboratories, Inc.). Standard curves were generated for mouse IgG1 and IgG2a concentrations (Biolegends, San Diego, CA, USA). In these experiments we used 3 mice in each group and the results are a summary of 3 independent experiments, thus, 18 mice were used to perform these experiments.

Immunization of rabbits with $r F B A$ for neutralization assay. Three-month-old New Zealand white (NZW) rabbits (Harlan Laboratories) were immunized as previously described (26). Briefly, 3-month-old white albino rabbits (Harlan Laboratories) were immunized intramuscularly (IM) with $200 \mu$ g HAT-rPtsA emulsified with CFA (1:1) in the first immunization or with IFA in booster immunizations in 2-week intervals. Two weeks after their final immunization, the rabbits were exsanguinated, and sera were prepared. The specificity of the antisera was confirmed by immunoblotting and ELISA.

Ex vivo neutralization of $S$. pneumoniae with anti-rFBA antisera. The WU2 strain was incubated at $37^{\circ} \mathrm{C}$ for $1 \mathrm{~h}$ either with diluted rabbit pre-immune or rabbit anti-rFBA antiserum. Subsequently, $500 \mathrm{CFU}$ of the bacteria were IP-inoculated into the BALB/c mice. Survival was monitored daily. In this experiment 10 mice were inoculated with $S$. pneumoniae treated ex vivo with sera obtained from rFBA/CFA/IFA immunized rabbits and 10 mice were inoculated with $S$. pneumoniae treated ex vivo with sera obtained from pre-immune sera from rabbits.

The WU2 strain was incubated at $37^{\circ} \mathrm{C}$ for $1 \mathrm{~h}$ either with 1:10 diluted $\mathrm{CBA} / \mathrm{N}^{x i d}$ mice pre-immune serum or with 1:25 diluted serum obtained from rFBA-immunized CBA/ $\mathrm{N}^{\text {xid }}$ mice. Subsequently, $10^{4} \mathrm{CFU}$ of bacteria were IV-inoculated into the BALB/c mice. Survival was monitored continuously. In these experiments $10 \mathrm{CBA} / \mathrm{N}^{x i d}$ were immunized with $\mathrm{rFBA}$ and 10 were immunized with the adjuvant only as described above. Sera were drawn and 10 mice were inoculated with bacteria treated ex vivo with sera obtained from rFBA immunized mice and 10 mice were inoculated with bacteria treated ex vivo with sera obtained from adjuvant immunized mice.

Statistical analysis. Log-rank and Wilcoxon signed-rank test, as determined by the GraphPad 6 software, were used to evaluate survival. Differences in cytokine levels or cell proliferation rates between two groups were analyzed with a two-tailed Student's t-test. Values of $\mathrm{p}<0.05$ were considered to indicate a statistically significant difference.

\section{Results}

$r F B A$ as a potential vaccine. The BALB/c mice immunized with rFBA + CFA/IFA/IFA [namely, with CFA and then with two IFA boosters] or with the adjuvants only (control) were challenged intranasally with a lethal dose of encapsulated $S$. pneumoniae serotype 3 strain WU2. The survival rates of the mice immunized with $\mathrm{rFBA}+\mathrm{CFA} / \mathrm{IFA} / \mathrm{IFA}$ were significantly higher than those of the control mice (Fig. 1A; log-rank test $\mathrm{p}<0.01$ ). The survival rates of the mice immunized with a DNA vaccine (namely, with $f b a$ inserted into the pVAC plasmid; $\mathrm{pVAC}^{f b a}$ ) were also significantly higher than those of the mice immunized with the respective adjuvant alone (Fig. 1B; log-rank test $\mathrm{p}<0.05$ ); however, the DNA vaccine was less protective (19\% survivors) than immunization with FBA + CFA/IFA/IFA (36\% survivors). The mice immunized with $\mathrm{rFBA}+$ alum demonstrated $26 \%$ survival, in comparison with $0 \%$ survival in the mice immunized with alum alone (Fig. 1C; Wilcoxon, p<0.05).

$\mathrm{CD}^{+} \mathrm{T}$-cell proliferation. To examine the extent of $\mathrm{CD} 4^{+} \mathrm{T}$-cell proliferation in response to $\mathrm{rBBA}$ stimulation, $\mathrm{CD}^{+} \mathrm{T}$-cells obtained from the rFBA + CFA/IFA/IFA-immunized mice were co-cultured with naïve APCs treated in vitro with $\mathrm{rFBA}$. The control groups included CD4- T-cells derived from the mice immunized with rFBA + CFA/IFA/IFA, $\mathrm{CD}^{+}$T-cells obtained from the mice immunized with the adjuvant alone, 
A

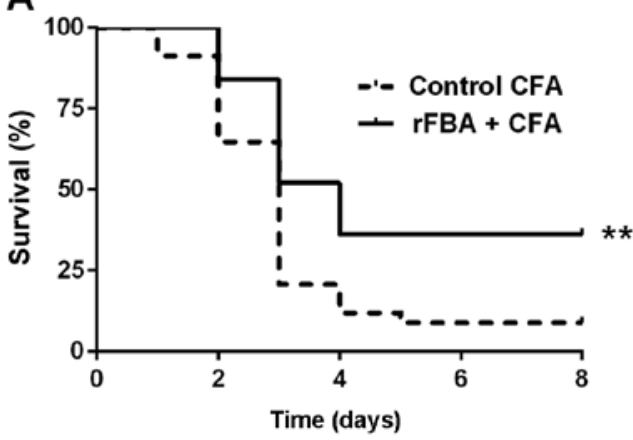

B

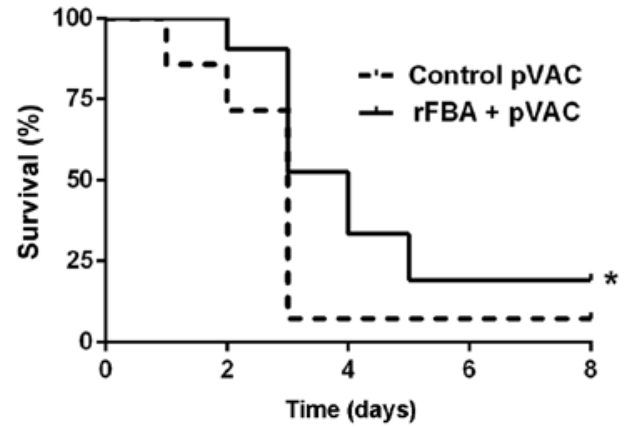

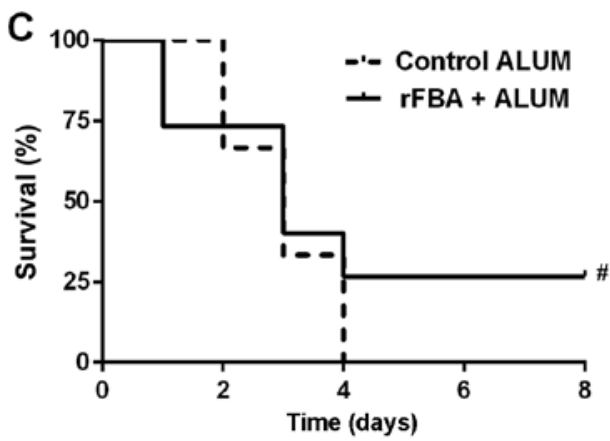

Figure 1. Vaccine potential of recombinant fructose-1,6-bisphosphate aldolase (rFBA). BALB/c mice were immunized subcutaneously (SC) with rFBA + complete Freund's adjuvant (CFA)/incomplete Freund's adjuvant (IFA)/IFA [(A) n=25], intramuscularly with pVAC ${ }^{\text {fba }}[(\mathrm{B}) \mathrm{n}=21]$, or intraperitoneally $(\mathrm{IP})$ with Imject Alum [(C) $n=15]$. Control mice were immunized with the respective adjuvants: SC with CFA/IFA [(A) n=34] or with an empty plasmid [(B) $n=14]$, or IP with Imject Alum $[(C) n=6]$. Immunized mice were inoculated intranasally with $10^{8} \mathrm{CFU}$ of the S. pneumoniae WU2 serotype. Survival was monitored daily. A Mann-Whitney $\mathrm{U}$ test revealed significantly higher survival for the rFBA + CFA/IFA/IFA- and pVAC ${ }^{f b a}$-immunized groups as compared with the respective control groups [(A) CFA/IFA/IFA, long-rank test ${ }^{*}$ p $<0.01$; (B) $\mathrm{pVAC}^{\text {fba }}$, long-rank test $\left.{ }^{*} \mathrm{p}<0.05\right)$. rFBA + Imject Alum group demonstrated increased protection that did not reach significance by log-rank but reached significance by Wilcoxon test $\left[(C){ }^{\#} \mathrm{p}<0.05\right]$ in comparison with their respective controls. The results presented are a summary of two independent experiments.

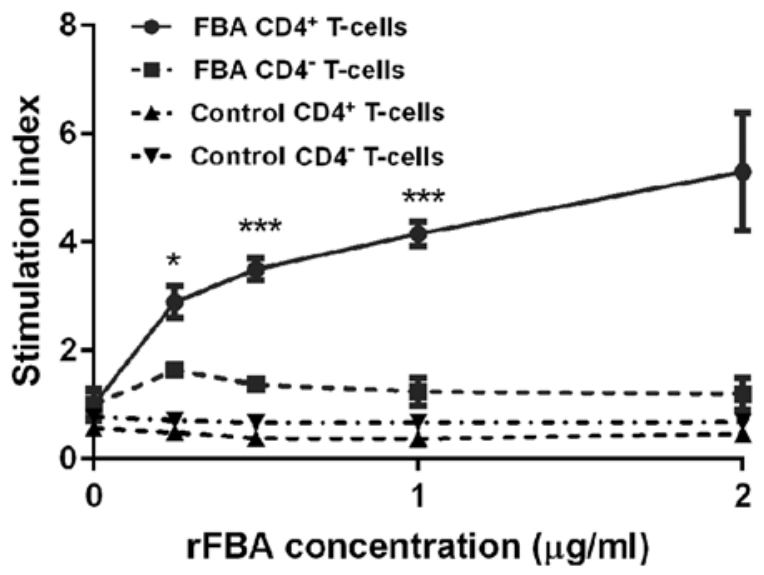

Figure 2. Memory $\mathrm{CD}^{+} \mathrm{T}$-cell proliferation in response to recombinant fructose-1,6-bisphosphate aldolase (rFBA) re-stimulation. The extent of proliferation, determined with a BrdU ELISA kit, was examined in the following groups of cells: i) $\mathrm{CD}^{+}{ }^{+} \mathrm{T}$-cells from mice immunized with rFBA + complete Freund's adjuvant (CFA)/incomplete Freund's adjuvant (IFA)/IFA (FBA CD4 ${ }^{+}$T-cells). All the following groups served as control groups: ii) $\mathrm{CD}^{+} \mathrm{T}$-cells derived from mice immunized with an adjuvant only (control $\mathrm{CD} 4^{+} \mathrm{T}$-cells). In addition, mononuclear cells depleted of CD4 ${ }^{+} \mathrm{T}$-cells, derived from iii) mice immunized with rFBA (control FBA CD4- T-cells) or from iv) mice immunized with an adjuvant only (control CD4- T-cells). All cells were co-cultured with mitomycin-treated spleen-derived naïve antigenpresenting cells (APCs) and incubated for $72 \mathrm{~h}$ with increasing concentrations of rFBA $(0-2 \mu \mathrm{g} / \mathrm{ml})$. The values represent the means of quadruplicate wells \pm standard deviation, and are expressed as the stimulation index, namely, the ratio of the extent of proliferation in the presence of rFBA to that in the absence of rFBA. Significant differences were found with the Student's t-test between the FBA CD4 ${ }^{+}$T-cells group and the control groups $\left({ }^{*} \mathrm{p} \leq 0.05\right.$ and $\left.{ }^{* * *} \mathrm{p}<0.001\right)$. Results are the summary of two independent experiments. and CD4- T-cells obtained from the mice immunized with the adjuvant alone. The $\mathrm{CD} 4^{+} \mathrm{T}$-cells derived from the mice immunized with rFBA + CFA/IFA/IFA showed a dose-dependent increase in the proliferation response upon re-stimulation with rFBA-pulsed APCs (Fig. 2; p<0.05). The $\mathrm{CD}^{+}{ }^{+} \mathrm{T}$-cells that were derived from the mice immunized with the adjuvant alone and from the $\mathrm{CD} 4^{+} \mathrm{T}$-cell-depleted groups did not respond to rFBA-pulsed APCs. These results demonstrate that rFBA induces an antigen-specific $\mathrm{CD} 4^{+} \mathrm{T}$-cell proliferative response.

Cytokine secretion from memory $C D 4^{+} T$-cells in response to re-stimulation with $r F B A$. To evaluate the nature of the immune response following immunization with $\mathrm{rFBA}$, we measured in vitro the cytokine secretion by $\mathrm{CD} 4^{+} \mathrm{T}$-cells in response to stimulation with rFBA-pulsed BMDCs. Two types of co-cultures were examined: $\mathrm{CD}^{+}{ }^{+} \mathrm{T}$-cells obtained from the mice immunized with rFBA + CFA/IFA/IFA ('FBA' culture), and $\mathrm{CD} 4^{+} \mathrm{T}$-cells obtained from the mice immunized with the adjuvant alone ('CFA' culture). Additional controls included cultures with BMDCs only ('DC-only' culture), $\mathrm{CD} 4{ }^{+} \mathrm{T}$-cells only, obtained from rFBA + CFA/IFA/IFA-immunized mice ('CD4-only' culture) and CD4 ${ }^{+} \mathrm{T}$-cells stimulated with concanavalin A (ConA) ('CD4 ${ }^{+} \mathrm{Con} \mathrm{A}^{\prime}$ culture).

The supernatant of the FBA culture contained levels of the Th1-related cytokines IFN- $\gamma$, IL-2 and tumor necrosis factor- $\alpha$ (TNF- $\alpha$ ) that were significantly higher than those in the supernatant of any of the other cultures (Fig. 3). More specifically, in the FBA culture, the levels of IFN- $\gamma$ were significantly higher than baseline (Fig. 3A; p<0.01) between 12 and $72 \mathrm{~h}$ 

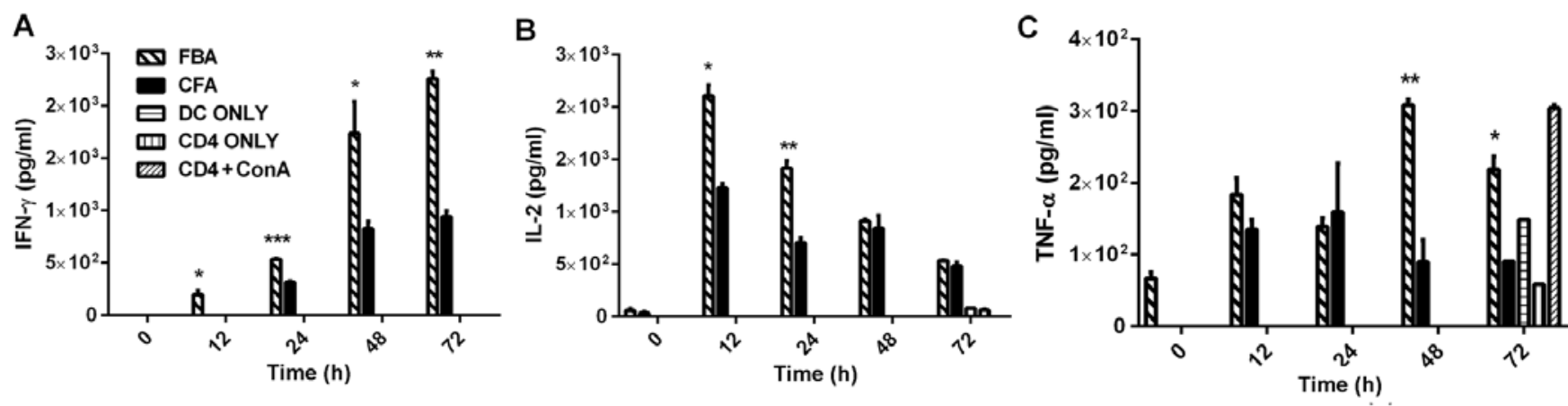

Figure 3. Thelper (Th)1-type cytokine secretion from memory $\mathrm{CD}^{+} \mathrm{T}$-cells in response to recombinant fructose-1,6-bisphosphate aldolase (rFBA) re-stimulation $\mathrm{CD}^{+}$T-cells were obtained from BALB/c mice immunized with rFBA + complete Freund's adjuvant (CFA)/incomplete Freund's adjuvant (IFA)/IFA ['FBA' cultures; the legend for the bar fill format that appears in (A) also applies to (B and C)], or from mice immunized with adjuvant alone ('CFA' cultures), followed by negative selection. CD4 $4^{+} \mathrm{T}$-cells that were obtained from BALB/c mice immunized with rFBA and CFA/IFA were used for the ' $\mathrm{CD} 4^{+}$only' control culture; BMDC cultures were used for the 'DC only' control cultures; and CD4 ${ }^{+} \mathrm{T}$-cells that were obtained from mice immunized with the adjuvant alone and stimulated with concanavalin A (ConA) were used for the ' $\mathrm{CD} 4^{+} \mathrm{ConA}$ ' control culture. $\mathrm{CD} 4^{+} \mathrm{T}$-cells in the control groups were stimulated with ConA. All CD4 ${ }^{+} \mathrm{T}-$ cells were coincubated with rFBA-pulsed BMDCs for $72 \mathrm{~h}$. The levels of cytokine secretion [(A) IFN- $\gamma$; (B) interleukin (IL)-2; (C) tumor necrosis factor (TNF)- $\alpha$ ] was measured by multiplex ELISA. The results represent the means \pm standard deviations of triplicate wells. A two-tailed Student's t-test found significant differences $(\mathrm{p}<0.05)$ between the 'FBA' cultures and 'CFA': cultures ( $\mathrm{p}<0.05,{ }^{* *} \mathrm{p}<0.01$ and $\left.^{* * *} \mathrm{p}<0.001\right)$. Results show one representative experiment out of two independent experiments.

A
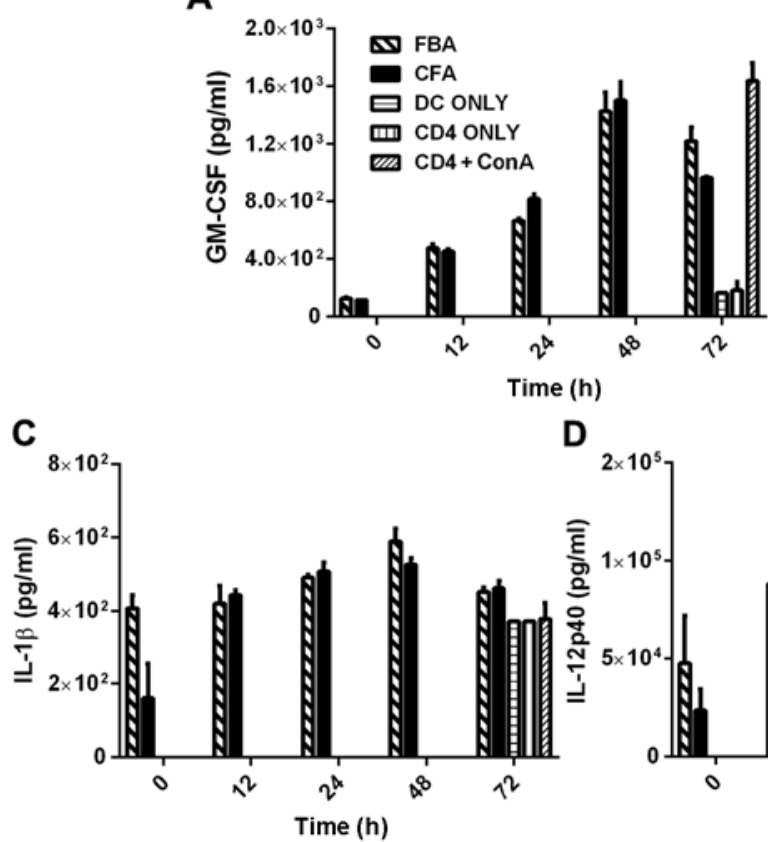

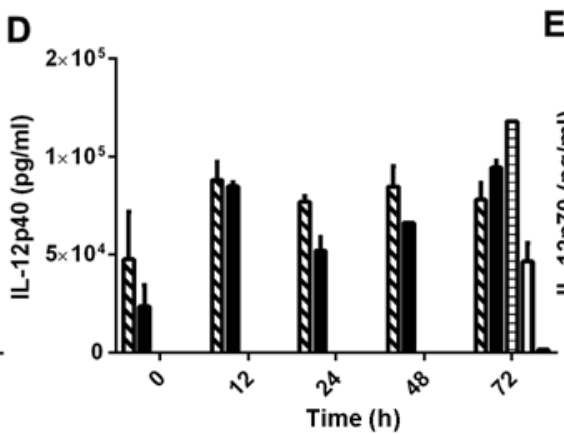

E
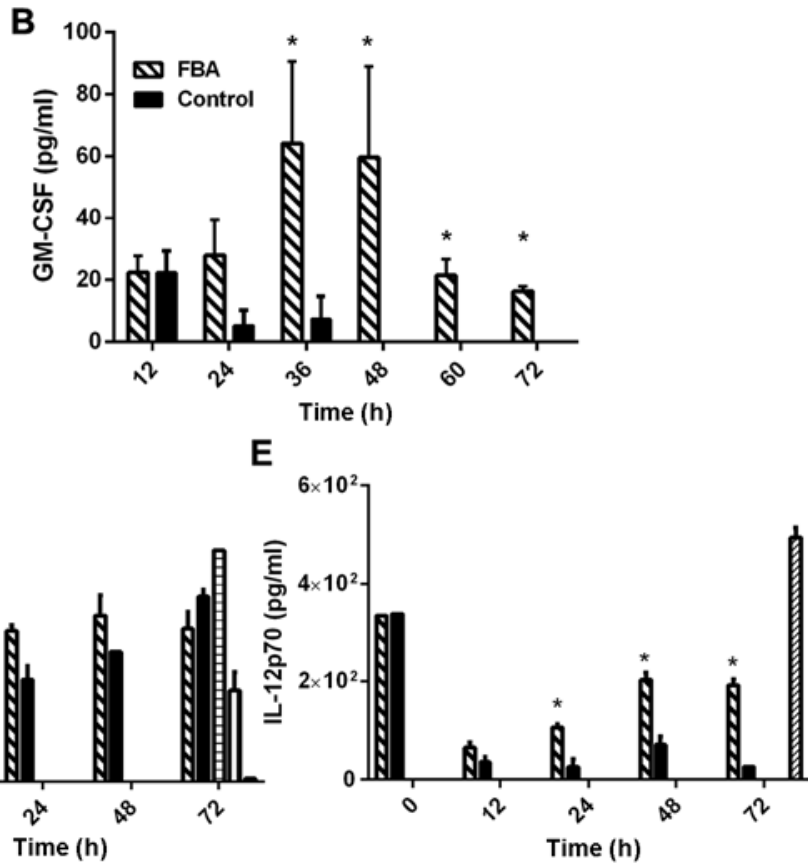

Figure 4. Pro-inflammatory-type cytokine secretion from memory CD4+ T-cells in response to recombinant fructose-1,6-bisphosphate aldolase (rFBA) restimulation. $\mathrm{CD}^{+}{ }^{+}$T-cells were obtained from BALB/c mice immunized with rFBA + complete Freund's adjuvant (CFA)/incomplete Freund's adjuvant (IFA)/IFA ['FBA' cultures; the legend for the bar fill format that appears in (A) applies also to (C-E)] or from mice immunized with the adjuvant alone ('CFA' cultures), followed by negative selection. CD4+ T-cells that were obtained from BALB/c mice immunized with rFBA and CFA/IFA were used for the 'CD4+ only' control cultures, and $\mathrm{CD}^{+} \mathrm{T}$-cells that were obtained from mice immunized with the adjuvant alone were stimulated with $5 \mu \mathrm{g} / \mathrm{ml}$ of concanavalin $\mathrm{A}(\mathrm{ConA})$ and used

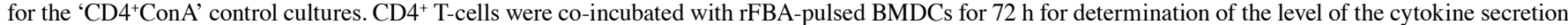
measured by multiplex ELISA. The results represent the means \pm standard deviation of triplicate wells. A two-tailed Student's t-test revealed no significant differences between the FBA and CFA cultures for (A) granulocyte-macrophage colony-stimulating factor (GM-CSF) (C) IL-1 $\beta$, (D) IL-12p40. (E) By contrast IL-12p70 demonstrated high levels at time $0 \mathrm{~h}$ that decreased at $12 \mathrm{~h}$ and significantly increased at 24,48 and $78 \mathrm{~h}(\mathrm{p}<0.05)$. Results are from one representative experiment out of two independent experiments. (B) GM-CSF/APC. CD4 ${ }^{+}$T-cells were obtained from BALB/c mice immunized with rFBA + CFA/IFA/IFA ('FBA' cultures), or from mice immunized with the adjuvant alone ('CFA' cultures), followed by negative selection. CD4 ${ }^{+}$T-cells were co-incubated with rFBA-pulsed spleenderived naïve antigen-presenting cells (APCs) for $72 \mathrm{~h}$. The results represent the mean \pm standard deviation of triplicate wells. Significant differences $(\mathrm{p}<0.05$ ) were determined by a two-tailed Student's t-test between the 'FBA' cultures and the 'CFA' cultures. Results are combined from two independent experiments.

following re-stimulation, and they peaked at $48-72 \mathrm{~h}$ (Fig. 3A); the levels of IL-2 peaked at $12 \mathrm{~h}(\mathrm{Fig} .3 \mathrm{~B} ; \mathrm{p}<0.05)$ and declined thereafter; and the levels of TNF- $\alpha$ peaked at $48 \mathrm{~h}$ (Fig. 3C; $\mathrm{p}<0.01)$ and were then reduced at $72 \mathrm{~h}$ (Fig. 3C; $<<0.05)$. Of note, the TNF- $\alpha$ level increased at $72 \mathrm{~h}$ in the $\mathrm{CD} 4^{+} \mathrm{ConA}$ group (as shown in Fig. 3C). No increase was observed in the secretion of IFN- $\gamma$, IL- 2 or TNF- $\alpha$ in the supernatants of the CFA, DC-only, CD4-only, or $\mathrm{CD} 4{ }^{+} \mathrm{ConA}$ cultures. 
A

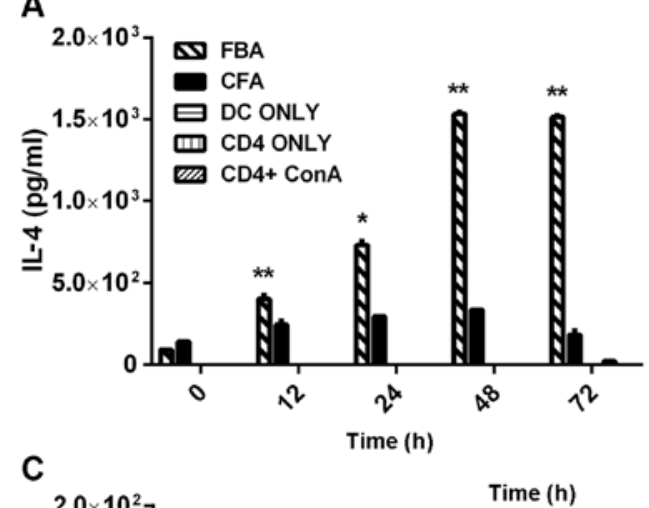

B

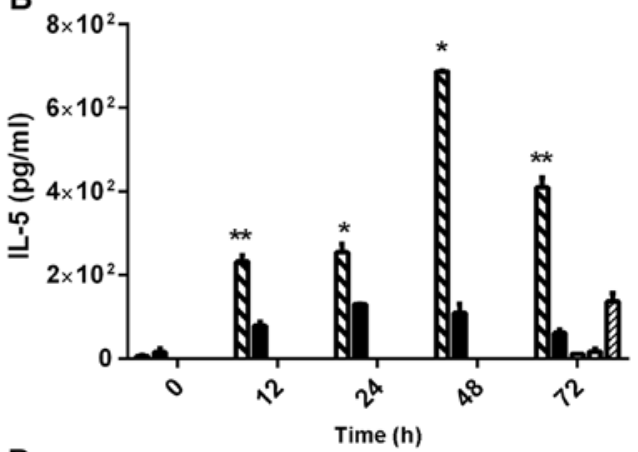

D

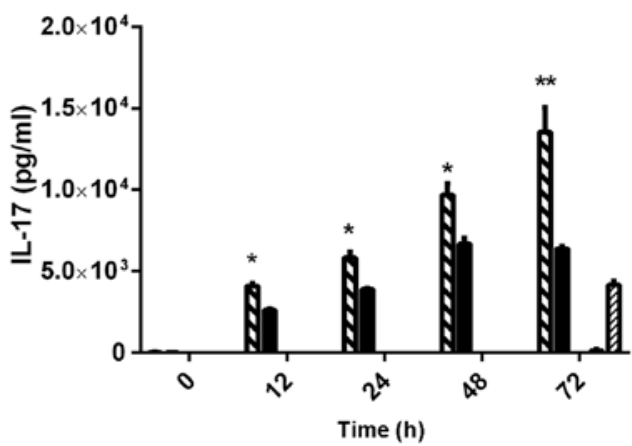

Figure 5. T helper (Th)2- and Th17-type cytokine secretion from memory CD4 ${ }^{+} \mathrm{T}$-cells in response to recombinant fructose-1,6-bisphosphate aldolase (rFBA) re-stimulation. $\mathrm{CD}^{+}$T-cells were obtained from BALB/c mice immunized with rFBA + complete Freund's adjuvant (CFA)/incomplete Freund's adjuvant (IFA) booster/IFA booster ['FBA' cultures; the legend for the bar fill format in (A) applies also to (B-D)], or from mice immunized with adjuvant alone ('CFA' cultures), followed by negative selection. $\mathrm{CD}^{+}{ }^{+} \mathrm{T}$-cells that were obtained from BALB/c mice immunized with rFBA and CFA/IFA were used for the 'CD4' only' control cultures, and $\mathrm{CD}^{+}{ }^{+} \mathrm{T}$-cells that were obtained from mice immunized with the adjuvant alone were used for the ' $\mathrm{CD} 4{ }^{+} \mathrm{ConA}$ ' control cultures. $\mathrm{CD} 4^{+} \mathrm{T}$-cells stimulated with $5 \mu \mathrm{g} / \mathrm{ml}$ of concanavalin A (ConA) served as CD4+ ConA group. CD4+ T-cells were co-incubated with rFBA-pulsed BMDCs for 72 h. The levels of cytokine [(A) IL-4; (B) IL-5; (C) IL-10; and (D) IL-17] secretion were measured by multiplex ELISA. The results represent the means \pm standard deviation of triplicate wells. Significant differences between groups were calculated with a two-tailed Student's t-test $\left({ }^{*} \mathrm{p}<0.05,{ }^{* *} \mathrm{p}<0.01\right.$ and $\left.{ }^{* * *} \mathrm{p}<0.001\right)$. Results are from one representative experiment out of two independent experiments.

High levels of the Th1-related cytokines, granulocytemacrophage colony-stimulating factor (GM-CSF), IL-1 $\beta$ IL-12p40, co-cultured with the rFBA-stimulated BMDCs, were found in the supernatants of the FBA and CFA cultures (Fig. 4A, C and D). No such stimulation was observed in the BMDC-only or in the CD4-only cultures. Notably, in the supernatant of $\mathrm{CD}^{+}{ }^{+} \mathrm{T}$-cells that were obtained from the rFBAimmunized mice and co-cultured with naïve spleen-derived APCs treated with rFBA, the levels of GM-CSF significantly increased at 36 and $48 \mathrm{~h}$ following co-culture initiation (Fig. 4B; p<0.05) and declined thereafter (Fig. 4). However, high levels of GM-CSF were observed in the $\mathrm{CD}^{+} \mathrm{ConA}$ cultures (Fig. 4A). IL-1 $\beta$ and IL-12p40 were detected in the supernatant of DC-only cultures (Fig. 4C and D, respectively) and in the supernatant of CD4-only cultures (at $<3 \%$ ), probably due to residual APCs in the supernatant following the negative selection procedure. Seventy-two hours following the initiation of the cultures, the levels of IL- $1 \beta$ increased to a similar extent in all the control cultures, while the levels of IL-12p40 decreased in the $\mathrm{CD}^{+} \mathrm{ConA}$ culture. The IL-12p70 levels were elevated in the FBA and CFA cultures at the time of initiation of the co-cultures and declined at $12 \mathrm{~h}$ after culture initiation. The levels of IL-12p70 in the FBA culture co-cultured with BMDCs increased from the reduced levels at $12 \mathrm{~h}$ following the initiation of the co-cultures and reached a plateau at $48 \mathrm{~h}$ (Fig. 4E; p $<0.05$ ); this pattern was not observed in any of the control cultures.
The supernatants of the FBA cultures demonstrated significantly higher levels of the Th2-related cytokines, IL-4, IL-5 and IL-10, at 12-48 $\mathrm{h}$ after co-incubation with the rFBA-pulsed BMDCs (Fig. 5A-C, respectively). As compared with their baseline levels, the levels of each of those three cytokines peaked at $48 \mathrm{~h}(\mathrm{p}<0.05)$; then, the levels of IL-4 remained elevated (Fig. 5A; p<0.05), whereas the levels of IL-5 (Fig. 5B) and IL-10 (Fig. 5C) declined, remaining higher than their baseline levels ( $\mathrm{p}<0.05$ for each cytokine). The secretion of IL-4, IL-5 and IL-10 was significantly decreased in all control cultures, except for an increase in IL-10 in the $\mathrm{CD} 4{ }^{+} \mathrm{ConA}$ culture (Fig. 5C).

The levels of the Th17-related cytokine, IL-17A, increased significantly (from $34 \mathrm{pg} / \mathrm{ml}$ to $13,500 \mathrm{pg} / \mathrm{ml}$; Fig. 5D; p $<0.05$ ) in the FBA culture at $72 \mathrm{~h}$ following the co-incubation of the CD4 ${ }^{+}$T-cells with the rFBA-pulsed BMDCs (Fig. 5D). Such an increase was not observed in any of the control cultures.

Concentrations of anti-rFBA IgG1 and IgG2a subtypes and protective ability of anti-rFBA antiserum. In addition to the cytokine profile expressed in vitro, we determined the concentrations of IgG1 and IgG2a antibodies in sera obtained from the mice immunized with rFBA + CFA/IFA/IFA or with CFA/IFA/IFA alone (control). The mice immunized with rFBA + CFA/IFA/IFA showed anti-rFBA IgG1 (Fig. 6A; $\mathrm{p}<0.001)$ and anti-rFBA IgG2a (Fig. 6A; $\mathrm{p}<0.05)$ titers that were significantly higher than those in the control mice (Fig. 6A). 
A

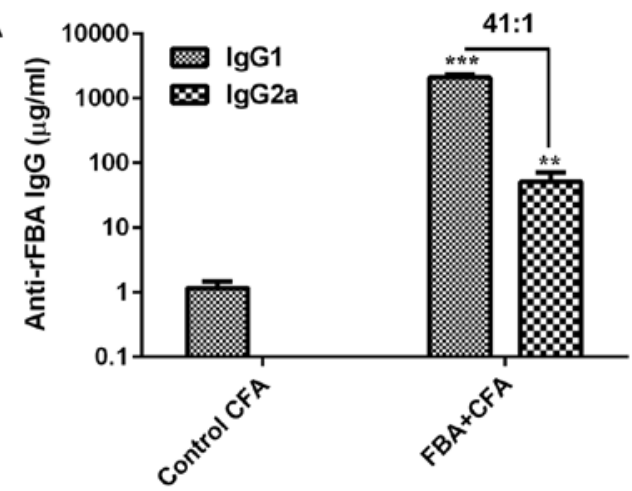

B

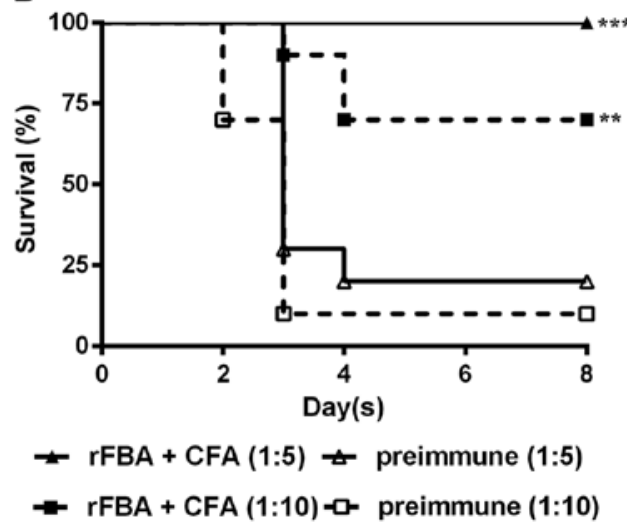

C

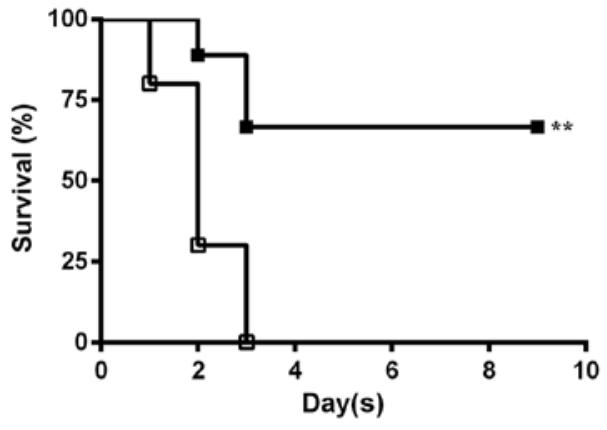

rFBA + CFA $(1: 25)$ — preimmune $(1: 10)$

Figure 6. Anti-recombinant fructose-1,6-bisphosphate aldolase (rFBA) antibodies: IgG1 and IgG2a subtypes and their S. pneumoniae neutralizing ability. (A) BALB/c mice were immunized with rFBA + complete Freund's adjuvant (CFA)/incomplete Freund's adjuvant (IFA)/IFA. Control mice were immunized with CFA/IFA/IFA alone. Two weeks following the third immunization, serum concentrations of IgG1 and IgG2a antibodies to rFBA were determined. A two-tailed Student's t-test revealed significant differences in the concentrations of $\operatorname{IgG1}(\mathrm{p}<0.001)$ and $\operatorname{IgG2a}(\mathrm{p}<0.05)$ in sera obtained from rFBA-immunized mice, as compared with the negative control. The presented results were summarized from two independent ELISA experiments. Two or three mice were immunized in each group. (B) S. pneumoniae serotype 3 strains WU2 were incubated at 1:5 or 1:10 dilutions with either preimmune rabbit serum or with rabbit anti-rFBA antiserum. Then, $500 \mathrm{CFU}$ of WU2 were inoculated intraperitoneally in BALB/c mice and survival was monitored daily for 7 days. Mice inoculated with anti-rFBA antiserum survived significantly longer than mice inoculated with pre-immune-treated bacteria (1:5 dilution, $\log$-rank test ${ }^{* * *} \mathrm{p}<0.001 ; 1: 10$ dilution (log-rank test $\left.{ }^{* *} \mathrm{p}<0.01\right)$. Each group comprised 10 mice. (C) WU2 strains were incubated at a 1:10 dilution with preimmune serum obtained from CBA/ $\mathrm{N}^{\mathrm{x} i d}$ mice or at a 1:25 dilution with serum obtained from CBA/ $\mathrm{N}^{x i d}$ mice immunized with $\mathrm{rFBA}$. Then, $10^{4} \mathrm{CFU}$ of WU2 strain were inoculated intravenously in BALB/c mice and survival was monitored continuously. BALB/c mice inoculated with bacteria incubated ex vivo with sera obtained from rFBA-immunized CBA/N ${ }^{x i d}$ survived significantly longer than mice inoculated with preimmune-treated bacteria (log-rank test $\left.{ }^{*}<0.01\right)$. Each group comprised 10 mice.

Analysis of the concentration ratio of IgG1 to IgG2a antibodies showed that immunization with $\mathrm{rFBA}+\mathrm{CFA} / \mathrm{IFA} / \mathrm{IFA}$ resulted in an $\mathrm{IgG} 1 / \mathrm{IgG} 2 \mathrm{a}$ ratio of 41 .

We then investigated the ability of the serum obtained from the rFBA-immunized rabbits to neutralize $S$. pneumoniae virulence. The BALB/c mice inoculated IP with WU2 bacteria that were pre-incubated ex vivo with rabbit anti-rFBA antiserum survived significantly longer (Fig. 6B; $\mathrm{p}<0.01)$ than the mice inoculated with bacteria treated with pre-immune rabbit serum (Fig. 6B). In addition, the BALB/c mice inoculated intravenously with a lethal dose of WU2 preincubated ex vivo with CBA/ $\mathrm{N}^{x i d}$ mouse anti-rFBA antiserum survived significantly longer than the mice inoculated with bacteria pre-incubated in vitro with mouse pre-immune serum (Fig. 6C; $\mathrm{p}<0.01$ ) .

\section{Discussion}

The surface localization of FBA has been previously demonstrated by immunoblotting and MALDI-TOF analysis of the bacterial cell wall (22) and by flow cytometric analysis of live bacteria stained with rabbit anti-rFBA antibodies (24). rFBA in the presence of alum has been shown to elicit a protective immune response in a mouse lethal challenge model (22). Thus, similar to other glycolytic enzymes $(26,27)$, FBA was suspected to have important functions other than its principal role as a cytoplasmic enzyme in glycolysis. Indeed, FBA was later found to mediate the adhesion of $S$. pneumoniae to host cells, as FBA and anti-FBA antibodies inhibited $S$. pneumoniae adhesion to A549 cells (24). In addition, using a peptide combinatorial library expressed in the filamentous phage, FCR was identified as the putative receptor of FBA. A peptide derived from FCR inhibited $S$. pneumoniae adhesion to A549 cells in vitro and prevented disease development in vivo in the mouse model following $S$. pneumoniae challenge (24). In the present study, we aimed to elucidate the nature of the protective immune response elicited by rFBA.

A major challenge in the development of subunit vaccines is the development of an efficient adjuvant or of a lymph node delivery system that would replace the highly potent CFA adjuvant (28-31). Aluminum salts elicit purely Th2-type responses (28), DNA vaccines elicit mainly Th1-type immune responses (by interacting with TLR9) (29), and CFA/IFA adjuvants elicit both a Th1-type (30) and a Th2-type (31) immune 
responses. A Th17-type response was previously observed in experimental autoimmune encephalomyelitis induced by immunization with myelin-derived peptides in CFA (32), and, therefore, we suspected that a Th17-type response will be induced in the presence of CFA as the adjuvant. Th17 has recently been shown to be associated with protective immunity against $S$.pneumoniae (34). Despite extensive efforts to develop new adjuvants, none has thus far surpassed the adjuvancy capacity of CFA $(5,33)$. CFA/IFA adjuvants are widely used in preclinical studies investigating candidates for a $S$. pneumoniae protein-based vaccine (34-36)

In the present experiments, the protection observed against a lethal $S$. pneumoniae challenge following immunization with rFBA in the presence of CFA/IFA surpassed the protection observed following immunization with $\mathrm{pVAC}^{f b a}$ or of $\mathrm{rFBA}$ in the presence of alum salt. Intranasal inoculation of mice with a whole cell vaccine (WCV) in the presence of cholera toxin or labile toxin, or of their non-toxic mutated derivatives, has been shown to elicit protection against intranasal inoculation with S. pneumoniae (37), which was Th17-dependent and antibody-independent (38). However, parenteral immunization with a WCV in the presence of alum as the adjuvant, either subcutaneously or intramuscularly, elicited a mucosal and systemic protection that was antibody dependent and T-cellindependent (39). WCVs contain pathogen-associated molecular patterns (PAMPs), such as lipoprotein and lipoteichoic acid that interact with TLR2, pneumolysin that interacts with TLR4, or peptidoglycan that interacts with nucleotide-binding oligomerization domain containing 2 (NOD2), which may contribute to the protective immune response elicited by the host (40). Lipidated membrane proteins have also been shown to elicit an increase in Th17 response and improve protection in comparison with non-lipidated proteins as a result of TLR2 activation (41). We suspected that the better protection following immunization with a single protein and with CFA/IFA as the adjuvant will elicit protection of the three arms of the immune response due to the mycobacterial components of CFA (40).

In this study, initial experiments performed on $\mathrm{CD}^{+}{ }^{+}$T-cells co-incubated with rFBA-stimulated APCs revealed a significantly increased proliferation of memory $\mathrm{CD}^{+}{ }^{+} \mathrm{T}$-cells in comparison with the following three control groups: CD4- T-cells obtained from the rFBA-immunized mice, $\mathrm{CD}^{+}{ }^{+} \mathrm{T}$-cells obtained from the mice immunized with the adjuvant only, and CD4- T-cells obtained from the mice immunized with the adjuvant only. The extent of CD4+ ${ }^{+}$-cell proliferation was similar to that described for other bacterial protein immunogens $(42,43)$.

The nature of the adaptive immune response to rFBA was examined by analyzing the cytokine secretion profile in the co-cultures of rFBA-pulsed naïve BMDCs and CD4 ${ }^{+} \mathrm{T}$-cells obtained from rFBA-immunized mice. In the supernatant of those cultures, the levels of IL- 2 , IFN- $\gamma$, TNF- $\alpha$, IL-12p70, IL-4, IL-5, IL-10 and IL-17 were significantly higher than those in the supernatants of the co-cultures of rFBA-treated BMDCs with $\mathrm{CD}^{+} \mathrm{T}$-cells obtained from the mice immunized with the adjuvant only. The supernatants of the $\mathrm{CD} 4^{+} \mathrm{T}$-cells obtained from the rFBA-immunized mice in the absence of BMDCs did not show an increased cytokine secretion. Similarly, the CD4- T-cells obtained from either the rFBA + CFA/IFA/IFA or the adjuvant only-immunized mice did not show increased cytokine secretion. This finding confirms the importance of the cross-talk between $\mathrm{CD}^{+}{ }^{+} \mathrm{T}$-cells and rFBA-treated dendritic cells for the secretion of those cytokines, which are known to be secreted from Th1-, Th2- and Th17-type memory CD4 ${ }^{+}$T-cells $(44,45)$.

The secretion of IL-2 peaked as early as $12 \mathrm{~h}$ following the initiation of the co-culture, and subsequently decreased. This temporal pattern is in accordance with the known secretion pattern of IL-2, which is rapid and transient, and the decrease in IL-2 production was due to the negative feedback loop required to limit IL-2 production during helper T-cell differentiation (46). The significantly increased secretion of IFN- $\gamma$ that was detected in this study is consistent with that of previous studies on children, which demonstrated the importance of IFN- $\gamma$ for the naturally acquired immune response to $S$. pneumoniae (47) and for the acquired immune response to $S$. pneumoniae proteins in mice (48). In this study, the secretion of IL-2 and IFN- $\gamma$ cytokines suggests the existence of a Th1-type response to immunization with rFBA. The significantly increased secretion of the proinflammatory cytokine TNF- $\alpha$ is in accordance with previous research that demonstrated the importance of TNF- $\alpha$ in the development of the adaptive humoral immune response to rPspA following immunization with unencapsulated R36A (49).

The levels of GM-CSF, IL-12p40 and IL-1 $\beta$ observed in the cultures of $\mathrm{CD}^{+}{ }^{+} \mathrm{T}$-cells obtained from the rFBA-immunized mice were insignificant compared to those in $\mathrm{CD} 4^{+} \mathrm{T}$-cells obtained from the adjuvant-immunized mice. Dendritic cell maturation was performed by exposing the cells to LPS prior to stimulation with rFBA. Thus, the increased levels of the GM-CSF, IL-12p40 and IL-1 $\beta$ cytokines were probably due to the effect of LPS on the dendritic cells, as was described previously (50). Indeed, a significant increase was observed in the levels of GM-CSF in the supernatant of $\mathrm{CD}^{+}{ }^{+} \mathrm{T}$-cells that were obtained from the rFBA-immunized mice and co-cultured with APCs pulsed with rFBA but not treated with LPS, as compared with those observed in the supernatant of $\mathrm{CD} 4^{+} \mathrm{T}$-cells that were obtained from the adjuvant-immunized mice and co-cultured with rFBA-pulsed APCs (Fig. 4B).

The levels of IL-12p70 detected in the culture supernatant of $\mathrm{CD}^{+}{ }^{+} \mathrm{T}$-cells obtained from the rFBA-immunized mice and co-cultured with the rFBA-treated BMDCs were significantly higher than those detected in the culture supernatant of $\mathrm{CD} 4^{+} \mathrm{T}$-cells obtained from the adjuvant-immunized mice in the presence of rFBA-treated BMDCs. This phenomenon was not observed in the rFBA-treated BMDCs co-cultured with $\mathrm{CD}^{+}{ }^{+} \mathrm{T}$-cells obtained from the adjuvant-immunized mice, suggesting that a cross-talk exists between $\mathrm{CD} 4^{+} \mathrm{T}$-cells and the rFBA-treated BMDCs. Indeed, such a cross-talk is crucial in the development of Th1-type responses, as described previously (51).

A significant increase in the secretion of IL-4, IL-5 and IL-10 was observed in the supernatants of $\mathrm{CD}^{+} \mathrm{T}$-cells obtained from the rFBA-immunized mice co-cultured with the rFBA-treated BMDCs. The higher levels of IL-4 resemble those found after immunizing mice with rGroEL (52), PspA (53) or PsaA (54). The increased secretion of IL-4, IL-5 and IL-10 suggests that rFBA immunization elicits a Th2-type immune response, which may be important for protection. Recently, IL-10 has been shown to be important to avoid excessive tissue 
inflammation and to improve host survival, despite the fact that bacterial dissemination is less efficient in the presence of this cytokine (55).

The secretion of the IL-17 cytokine by $\mathrm{CD} 4^{+} \mathrm{T}$-cells co-cultured with the rFBA-treated BMDCs increased continuously throughout the $72 \mathrm{~h}$ of the experiment. This finding is in agreement with the findings of recent studies demonstrating the importance of IL-17 in protection against $S$. pneumoniae. The seminal studies of Malley and Anderson [reviewed in (8)] have shown that, in mice, the acquired protective immune response to pneumococcal colonization following intranasal immunization with heat-killed unencapsulated bacteria depends on $\mathrm{CD}^{+}$T-cells, and particularly on the Th17 arm of the immune response; however, it is antibody-independent (39).

In the present study, cytokines from the Th1, Th2 and Th17 arms of the immune response were induced following immunization with a single protein, rFBA. These results confirm previous findings obtained in vivo in the bronchoalveolar lavage and the serum of mice immunized with Lactobacillus lactis expressing the PppA protein from S. pneumoniae (56). Other studies performed with human $\mathrm{CD}^{+}{ }^{+} \mathrm{T}$-cells have demonstrated the dominance of both the Th17-type and Th1-type immune responses to $S$. pneumoniae $(9,10)$ or to $S$.pneumoniae proteins $(4,50)$. Parenteral immunization with attenuated WCV in the presence of alum elicited Th1-, Th2- and Th17-type cytokine expression that was an order of magnitude lower than that found in the present study (57). An alum-adjuvanted Staphylococcus aureus antigen [(clumping factor A (ClfA)] induced IL-17-dependent protection against Staphylococcal challenge (58). Therefore, the ability of alum to promote Th17-type responses appears to depend on the nature of the vaccine antigen; in particular, antigens with inherent immunomodulatory activity, such as killed bacteria, may synergize with the adjuvant to promote Th17-type responses.

ConA was used in the present study as a polyclonal non-specific stimulator for cytokine secretion. ConA is a member of the legume lectin family and binds specifically to internal and terminal $\alpha$-D-mannosyl and $\alpha$-D-glucosyl groups found in various sugars, glycoproteins and glycolipids (59). ConA binds the CD3 component of human T-cell receptors (60) and most of its stimulatory properties are similar to those of anti-CD3 and anti-TCR antibodies (61). The effect of ConA on T-cells is generally attributed to its binding to and cross-linking of the CD3 component of the TCR, thereby mimicking the physiological T-cell receptor ligand MHC-peptide complex (62). However, lectins are more potent stimulators of cell proliferation than anti-CD3 or anti-CD4 antibodies, possibly as a result of simultaneous activation of one or more co-stimulatory receptors. In addition, differences in substrate phosphorylation downstream from TCR following the binding of an MHC-peptide complex, in comparison to ConA activation of $\mathrm{CD}^{+}{ }^{+} \mathrm{T}$-cells, were reported (63). The activation of T-cells with ConA resulted in reduced secretion of IL-2 and IFN- $\gamma$ in comparison with stimulation with an antigen (64), suggesting that antigen-MHC or ConA activation of CD3 stimulates different levels of cytokine expression.

The type of antibody produced against rFBA and the importance of antibodies to protection were analyzed in the sera obtained from the rFBA-immunized mice. Immunizing mice with $\mathrm{rFBA}$ resulted in a median $\mathrm{IgG1} / \mathrm{IgG} 2$ a ratio of 41 , suggesting a primary Th2 response resulting in IgG1 antibody production, with a substantial Th1 response resulting in $\mathrm{IgG} 2 \mathrm{a}$ antibody production. In a previous study, the immunization of BALB/c mice with $\mathrm{rPspA}+$ alum induced an $\mathrm{IgG1} / \mathrm{IgG} 2$ a ratio of 1024, suggesting a strong Th2-biased response. However, immunization with a $p s p A$ DNA vaccine induced an $\operatorname{IgG} 1 / \operatorname{IgG} 2 \mathrm{a}$ ratio of 2 , suggesting a strong Th1 bias (65). Th1- and Th2-type immune responses are mutually exclusive in the presence of all the components of the immune system in vivo. Thus, the Th1 Th2 exclusion is never absolute but, rather, relative. The induction of both Th1- and Th2-type responses in vivo is in accordance with our in vitro results, in which Th1- and Th2-related cytokines were found upon exposure of the $\mathrm{CD} 4^{+} \mathrm{T}$-cells to rFBA-pulsed BMDCs. The expression of Th1- and Th2-type cytokines appeared simultaneously; suggesting that memory T-cells from these arms of the immune response are present in the rFBAimmunized mice. Activation in vitro with the rFBA-pulsed BMDCs elicited cytokine production from the Th1, Th2 and Th17 arms of the immune response. In vivo, re-exposure to an immunogen/pathogen may culminate in higher expression of one of the arms of the immune response relative to the others due to activation of control mechanisms that are lacking in the in vitro system. Furthermore, rabbit and mouse anti-rFBA antisera preincubated ex vivo with $S$. pneumoniae significantly neutralized bacterial virulence and thereby protected the mice against a S. pneumoniae lethal challenge, as compared with bacteria pre-incubated with pre-immune serum. This neutralization may result from interference in bacterial adhesion to host cells (66) and suggests that the antibodies also enhance phagocytosis of bacteria that shed their capsule during adhesion.

We conducted our experiments with both the rabbit and the mouse sera since different species have different immunoglobulin protein profiles. Humans and mice have five antibody isotypes ( $\operatorname{Ig} \mathrm{A}, \operatorname{IgD}$, $\operatorname{IgE}, \operatorname{IgG}$ and $\operatorname{IgM}$ ), whereas, in rabbits, four isotypes (IgA, IgE, IgG and $\operatorname{IgM}$ ) have been identified to date, to the best of our knowledge. In addition, rabbits have only one IgG subclass, whereas mice have five subclasses (IgG1, IgG2a, $\operatorname{IgG} 2 \mathrm{~b}, \operatorname{IgG} 2 \mathrm{c}$ and $\mathrm{IgG} 3$ ) and humans have four (IgG1, IgG2, IgG3 and IgG4). We have previously demonstrated that antirFBA antisera inhibit the adhesion of S.pneumoniae to cultured lung-derived epithelial cells (24). Similarly, antibodies to other S. pneumoniae adhesins, among which are PcpA and PsrP, inhibited the adhesion of $S$. pneumoniae to human respiratory epithelial cells $(15,67)$, and antibodies against PcpA were found to protect mice against a pneumococcal challenge (15). The exposure of bacterial cell-wall proteins occurs during bacterial adhesion to the host as a result of capsular shedding (66), which enables access and binding of the antibodies to their respective proteins and, possibly, facilitates their neutralization. Therefore, the observed protection of mice against a S. pneumoniae challenge by using anti-FBA antibodies may result from inhibition of bacterial adhesion to the host.

\section{Acknowledgements}

This study was supported by grants 4476,5540 and 3000003867 from the Israel Ministry of Health to Y.M.N.; grant 80904101 from BG Negev Technologies, Ben-Gurion University of the Negev, to Y.M.N.; grant 2506 from the Center of Emerging Diseases to Y.M.N.; and grant 613/04 from The Israel Academy of Science 
to Y.M.N., the Israeli Ministry of Commerce and Industry to Y.M.N.,the Israeli Ministry of Commerce and Industry to NasVax and Y.M.N., CAREPNEUMO from the European Commission to NasVax and Y.M.N. The study and some of the authors were partially funded by commercial companies (Nasvax Ltd. and Protea Vaccine Technologies Ltd.) through the BG Negev Technologies that is the commercialization arm of Ben-Gurion University of the Negev. The rFBA protein that is discussed in the manuscript is protected by several pending patents: US WO 03/082183; EP 1490104; PCT WO2010/029546 A2. The protein vaccine is at an early stage of preclinical studies. There are no marketed products to declare.

\section{References}

1. Dagan R, Poolman J and Siegrist CA: Glycoconjugate vaccines and immune interference: a review. Vaccine 28: 5513-5523, 2010

2. van der Poll T and Opal SM: Pathogenesis, treatment, and prevention of pneumococcal pneumonia. Lancet 374: 1543-1556, 2009.

3. Denoël P, Philipp MT, Doyle L, Martin D, Carletti G and Poolman JT: A protein-based pneumococcal vaccine protects rhesus macaques from pneumonia after experimental infection with Streptococcus pneumoniae. Vaccine 29: 5495-5501, 2011.

4. Schmid P, Selak S, Keller M, Luhan B, Magyarics Z, Seidel S, Schlick P, Reinisch C, Lingnau K, Nagy E and Grubeck-Loebenstein B: Th17/Th1 biased immunity to the pneumococcal proteins PcsB, StkP and PsaA in adults of different age. Vaccine 29: 3982-3989, 2011

5. Koff WC, Gust ID and Plotkin SA: Toward a human vaccines project. Nat Immunol 15: 589-592, 2014.

6. van Rossum AM, Lysenko ES and Weiser JN: Host and bacterial factors contributing to the clearance of colonization by Streptococcus pneumoniae in a murine model. Infect Immun 73: 7718-7726, 2005.

7. Basset A, Thompson CM, Hollingshead SK, Briles DE, Ades EW, Lipsitch $\mathrm{M}$ and Malley R: Antibody-independent, $\mathrm{CD}^{+}{ }^{+} \mathrm{T}-$-celldependent protection against pneumococcal colonization elicited by intranasal immunization with purified pneumococcal proteins. Infect Immun 75: 5460-5464, 2007.

8. Malley R and Anderson PW: Serotype-independent pneumococcal experimental vaccines that induce cellular as well as humoral immunity. Proc Natl Acad Sci USA 109: 3623-3627, 2012.

9. Mureithi MW, Finn A, Ota MO, Zhang Q, Davenport V, Mitchell TJ, Williams NA, Adegbola RA and Heyderman RS: $\mathrm{T}$ cell memory response to pneumococcal protein antigens in an area of high pneumococcal carriage and disease. J Infect Dis 200: 783-793, 2009.

10. Pido-Lopez J, Kwok WW, Mitchell TJ, Heyderman RS and Williams NA: Acquisition of pneumococci specific effector and regulatory $\mathrm{CD}^{+} \mathrm{T}$ cells localising within human upper respiratory-tract mucosal lymphoid tissue. PLoS Pathog 7: e1002396, 2011.

11. Rosenow C, Ryan P, Weiser JN, Johnson S, Fontan P, Ortqvist A and Masure HR: Contribution of novel choline-binding proteins to adherence, colonization and immunogenicity of Streptococcus pneumoniae. Mol Microbiol 25: 819-829, 1997.

12. Mann B, Thornton J, Heath R, Wade KR, Tweten RK, Gao G, El Kasmi K, Jordan JB, Mitrea DM, Kriwacki R, et al: Broadly protective protein-based pneumococcal vaccine composed of pneumolysin toxoid-CbpA peptide recombinant fusion protein. J Infect Dis 209: 1116-1125, 2014.

13. Glover DT, Hollingshead SK and Briles DE: Streptococcus pneumoniae surface protein PcpA elicits protection against lung infection and fatal sepsis. Infect Immun 76: 2767-2776, 2008.

14. Talkington DF, Brown BG, Tharpe JA, Koenig A and Russell H: Protection of mice against fatal pneumococcal challenge by immunization with pneumococcal surface adhesin A (PsaA). Microb Pathog 21: 17-22, 1996.

15. Rose L, Shivshankar P, Hinojosa E, Rodriguez A Sanchez CJ and Orihuela CJ: Antibodies against PsrP, a novel Streptococcus pneumoniae adhesin, block adhesion and protect mice against pneumococcal challenge. J Infect Dis 198: 375-383, 2008.
16. Daniels CC, Kim KH, Burton RL, Mirza S, Walker M, King J, Hale Y, Coan P, Rhee DK, Nahm MH and Briles DE: Modified opsonization, phagocytosis, and killing assays to measure potentially protective antibodies against pneumococcal surface protein A. Clin Vaccine Immunol 20: 1549-1558, 2013.

17. Giefing C, Meinke AL, Hanner M, Henics T, Bui MD, Gelbmann D, Lundberg U, Senn BM, Schunn M, Habel A, et al: Discovery of a novel class of highly conserved vaccine antigens using genomic scale antigenic fingerprinting of pneumococcus with human antibodies. J Exp Med 205: 117-131, 2008.

18. Pancholi V and Chhatwal GS: Housekeeping enzymes as virulence factors for pathogens. Int J Med Microbiol 293: 391-401, 2003.

19. Tunio SA, Oldfield NJ, Berry A, Ala'Aldeen DA, Wooldridge KG and Turner DP: The moonlighting protein fructose-1,6-bisphosphate aldolase of Neisseria meningitidis: surface localization and role in host cell adhesion. Mol Microbiol 76: 605-615, 2010.

20. Wu Z, Zhang $\mathrm{W}$ and $\mathrm{Lu} \mathrm{C}$ : Immunoproteomic assay of surface proteins of Streptococcus suis serotype 9. FEMS Immunol Med Microbiol 53: 52-59, 2008.

21. McCarthy JS, Wieseman M, Tropea J, Kaslow D, Abraham D, Lustigman S, Tuan R, Guderian RH and Nutman TB: Onchocerca volvulus glycolytic enzyme fructose-1,6-bisphosphate aldolase as a target for a protective immune response in humans. Infect Immun 70: 851-858, 2002.

22. Ling E, Feldman G, Portnoi M, Dagan R, Overweg K, Mulholland F, Chalifa-Caspi V, Wells J and MizrachiNebenzahl Y: Glycolytic enzymes associated with the cell surface of Streptococcus pneumoniae are antigenic in humans and elicit protective immune responses in the mouse. Clin Exp Immunol 138: 290-298, 2004.

23. Portnoi M, Ling E, Feldman G, Dagan R and MizrachiNebenzahl Y: The vaccine potential of Streptococcus pneumoniae surface lectin- and non-lectin proteins. Vaccine 24: 1868-1873, 2006.

24. Blau K, Portnoi M, Shagan M, Kaganovich A, Rom S, Kafka D, Chalifa Caspi V, Porgador A, Givon-Lavi N, Gershoni JM, et al: Flamingo cadherin: a putative host receptor for Streptococcus pneumoniae. J Infect Dis 195: 1828-1837, 2007.

25. Mori A, Oleszycka E, Sharp FA, Coleman M, Ozasa Y, Singh M, O'Hagan DT, Tajber L, Corrigan OI, McNeela EA and Lavelle EC: The vaccine adjuvant alum inhibits IL-12 by promoting PI3 kinase signaling while chitosan does not inhibit IL-12 and enhances Th1 and Th17 responses. Eur J Immunol 42: 2709-2719, 2012.

26. Chhatwal GS: Anchorless adhesins and invasins of Gram-positive bacteria: a new class of virulence factors. Trends Microbiol 10: 205-208, 2002.

27. Henderson B and Martin A: Bacterial virulence in the moonlight: multitasking bacterial moonlighting proteins are virulence determinants in infectious disease. Infect Immun 79: 3476-3491, 2011

28. Garçon N and Van Mechelen M: Recent clinical experience with vaccines using MPL- and QS-21-containing adjuvant systems. Expert Rev Vaccines 10: 471-486, 2011.

29. Moon JJ, Huang B and Irvine DJ: Engineering nano- and microparticles to tune immunity. Adv Mater 24: 3724-3746, 2012.

30. Keler T, He L, Ramakrishna V and Champion B: Antibodytargeted vaccines. Oncogene 26: 3758-3767, 2007.

31. Liu H, Moynihan KD, Zheng Y, Szeto GL, Li AV, Huang B, Van Egeren DS, Park C and Irvine DJ: Structure-based programming of lymph-node targeting in molecular vaccines. Nature 507: 519-522, 2014.

32. Libbey JE and Fujinami RS: Experimental autoimmune encephalomyelitis as a testing paradigm for adjuvants and vaccines. Vaccine 29: 3356-3362,2011.

33. Delany I, Rappuoli R and De Gregorio E: Vaccines for the 21st century. EMBO Mol Med 6: 708-720, 2014.

34. Seiberling M, Bologa M, Brookes R, Ochs M, Go K, Neveu D, Kamtchoua T, Lashley P, Yuan T and Gurunathan S: Safety and immunogenicity of a pneumococcal histidine triad protein D vaccine candidate in adults. Vaccine 30: 7455-7460, 2012.

35. Adamou JE, Heinrichs JH, Erwin AL, Walsh W, Gayle T, Dormitzer M, Dagan R, Brewah YA, Barren P, Lathigra R, et al: Identification and characterization of a novel family of pneumococcal proteins that are protective against sepsis. Infect Immun 69: 949-958, 2001. 
36. Wizemann TM,Heinrichs JH, Adamou JE, Erwin AL, Kunsch C, Choi GH, Barash SC, Rosen CA, Masure HR, Tuomanen E, et al: Use of a whole genome approach to identify vaccine molecules affording protection against Streptococcus pneumoniae infection. Infect Immun 69: 1593-1598, 2001

37. Lu YJ, Yadav P, Clements JD, Forte S, Srivastava A Thompson CM, Seid R, Look J, Alderson M, Tate A, et al: Options for inactivation, adjuvant, and route of topical administration of a killed, unencapsulated pneumococcal whole-cell vaccine. Clin Vaccine Immunol 17: 1005-1012, 2010.

38. Lu YJ, Leite L, Gonçalves VM, Dias WO, Liberman C, Fratelli F, Alderson M, Tate A, Maisonneuve JF, Robertson G, et al: GMP-grade pneumococcal whole-cell vaccine injected subcutaneously protects mice from nasopharyngeal colonization and fatal aspiration-sepsis. Vaccine 28: 7468-7475, 2010.

39. Malley R, Srivastava A, Lipsitch M, Thompson CM, Watkins C, Tzianabos A and Anderson PW: Antibody-independent, interleukin-17A-mediated, cross-serotype immunity to pneumococci in mice immunized intranasally with the cell wall polysaccharide. Infect Immun 74: 2187-2195, 2006.

40. Kumar S, Ingle H, Prasad DV and Kumar H: Recognition of bacterial infection by innate immune sensors. Crit Rev Microbiol 39: 229-246, 2013.

41. Moffitt K, Skoberne M, Howard A, Gavrilescu LC, Gierahn T, Munzer S, Dixit B, Giannasca P, Flechtner JB and Malley R: Toll-like receptor 2-dependent protection against pneumococcal carriage by immunization with lipidated pneumococcal proteins. Infect Immun 82: 2079-2086, 2014.

42. Liu X, Wetzler LM and Massari P: The PorB porin from commensal Neisseria lactamica induces Th1 and Th2 immune responses to ovalbumin in mice and is a potential immune adjuvant. Vaccine 26: 786-796, 2008.

43. Zhang Q, Bagrade L, Bernatoniene J, Clarke E, Paton JC, Mitchell TJ, Nunez DA and Finn A: Low CD4 T cell immunity to pneumolysin is associated with nasopharyngeal carriage of pneumococci in children. J Infect Dis 195: 1194-1202, 2007.

44. Mosmann TR and Coffman RL: TH1 and TH2 cells: Different patterns of lymphokine secretion lead to different functional properties. Annu Rev Immunol 7: 145-173, 1989.

45. Harrington LE, Mangan PR and Weaver CT: Expanding the effector CD4 T-cell repertoire: the Th17 lineage. Curr Opin Immunol 18: 349-356, 2006.

46. Villarino AV, Tato CM, Stumhofer JS, Yao Z, Cui YK, Hennighausen L, O'Shea JJ and Hunter CA: Helper T cell IL-2 production is limited by negative feedback and STAT-dependent cytokine signals. J Exp Med 204: 65-71, 2007.

47. van den Biggelaar AH, Pomat WS, Phuanukoonnon S, Michael A, Aho C, Nadal-Sims MA, Devitt CJ, Jacoby PA, Hales BJ, Smith WA, et al: Effect of early carriage of Streptococcus pneumoniae on the development of pneumococcal protein-specific cellular immune responses in infancy. Pediatr Infect Dis J 31: 243-248, 2012

48. Ferreira DM, Darrieux M, Silva DA, Leite LC, Ferreira JM Jr, Ho PL, Miyaji EN and Oliveira ML: Characterization of protective mucosal and systemic immune responses elicited by pneumococcal surface protein PspA and PspC nasal vaccines against a respiratory pneumococcal challenge in mice. Clin Vaccine Immunol 16: 636-645, 2009.

49. Khan AQ, Shen Y, Wu ZQ, Wynn TA and Snapper CM: Endogenous pro- and anti-inflammatory cytokines differentially regulate an in vivo humoral response to Streptococcus pneumoniae. Infect Immun 70: 749-761, 2002.

50. Wei WC, Su YH, Chen SS, Sheu JH and Yang NS: GM-CSF plays a key role in zymosan-stimulated human dendritic cells for activation of Th1 and Th17 cells. Cytokine 55: 79-89, 2011.

51. Tourret M, Guégan S, Chemin K, Dogniaux S, Miro F, Bohineust A and Hivroz C: T cell polarity at the immunological synapse is required for CD154-dependent IL-12 secretion by dendritic cells. J Immunol 185: 6809-6818, 2010

52. Cao J, Zhang X, Gong Y, Zhang Y, Cui Y, Lai X, Yin Y, Li M, Li D and Zhang L: Protection against pneumococcal infection elicited by immunization with multiple pneumococcal heat shock proteins. Vaccine 31: 3564-3571, 2013.
53. Li Y, Wang S, Scarpellini G, Gunn B, Xin W, Wanda SY, Roland KL and Curtiss R III: Evaluation of new generation Salmonella enterica serovar Typhimurium vaccines with regulated delayed attenuation to induce immune responses against PspA. Proc Natl Acad Sci USA 106: 593-598, 2009.

54. Miyaji EN, Dias WO, Gamberini M, Gebara VC, Schenkman RP, Wild J, Riedl P, Reimann J, Schirmbeck R and Leite LC: PsaA (pneumococcal surface adhesin A) and PspA (pneumococcal surface protein A) DNA vaccines induce humoral and cellular immune responses against Streptococcus pneumoniae. Vaccine 20: 805-812, 2001.

55. Peñaloza HF, Nieto PA, Muñoz-Durango N, Salazar-Echegarai FJ, Torres J, Parga MJ, Alvarez-Lobos M, Riedel CA, Kalergis AM and Bueno SM: Interleukin-10 plays a key role in the modulation of neutrophils recruitment and lung inflammation during infection by Streptococcus pneumoniae. Immunology 146: 100-112, 2015.

56. Vintiñi E, Villena J, Alvarez S and Medina M: Administration of a probiotic associated with nasal vaccination with inactivated Lactococcus lactis-PppA induces effective protection against pneumoccocal infection in young mice. Clin Exp Immunol 159: 351-362, 2010.

57. Wu K, Yao R, Wang H, Pang D, Liu Y, Xu H, Zhang S, Zhang X and Yin Y: Mucosal and systemic immunization with a novel attenuated pneumococcal vaccine candidate confer serotype independent protection against Streptococcus pneumoniae in mice. Vaccine 32: 4179-4188, 2014.

58. Narita K, Hu DL, Mori F, Wakabayashi K, Iwakura Y and Nakane A: Role of interleukin-17A in cell-mediated protection against Staphylococcus aureus infection in mice immunized with the fibrinogen-binding domain of clumping factor A. Infect Immun 78: 4234-4242, 2010.

59. Poretz RD and Goldstein IJ: Protein-carbohydrate interaction. On the mode of bonding of aromatic moieties to concanavalin $\mathrm{A}$, the phytohemagglutinin of the jack bean. Biochem Pharmacol 20: 2727-2739, 1971.

60. Chilson OP and Kelly-Chilson AE: Mitogenic lectins bind to the antigen receptor on human lymphocytes. Eur J Immunol 19: 389-396, 1989.

61. Fleischer B: Activation of human T lymphocytes II. Involvement of the $\mathrm{T} 3$ antigen in polyclonal $\mathrm{T}$ cell activation by mitogenic lectins and oxidation. Eur J Immunol 14: 748-752, 1984.

62. Weiss A, Imboden J, Hardy K, Manger B, Terhorst C and Stobo J: The role of the T3/antigen receptor complex in T-cell activation. Annu Rev Immunol 4: 593-619, 1986.

63. Pani G, Colavitti R, Borrello S and Galeotti T: Endogenous oxygen radicals modulate protein tyrosine phosphorylation and JNK-1 activation in lectin-stimulated thymocytes. Biochem J 347: 173-181, 2000.

64. Callahan TA and Moynihan JA: Contrasting pattern of cytokines in antigen-versus mitogen-stimulated splenocyte cultures from chemically denervated mice. Brain Behav Immun 16: 764-773, 2002.

65. Vadesilho CF, Ferreira DM, Moreno AT, Chavez-Olortegui C, Machado de Avila RA, Oliveira ML, Ho PL and Miyaji EN: Characterization of the antibody response elicited by immunization with pneumococcal surface protein A (PspA) as recombinant protein or DNA vaccine and analysis of protection against an intranasal lethal challenge with Streptococcus pneumoniae. Microb Pathog 53: 243-249, 2012.

66. Hammerschmidt S, Wolff S, Hocke A, Rosseau S, Müller E and Rohde M: Illustration of pneumococcal polysaccharide capsule during adherence and invasion of epithelial cells. Infect Immun 73: 4653-4667, 2005

67. Khan MN, Sharma SK, Filkins LM and Pichichero ME: PcpA of Streptococcus pneumoniae mediates adherence to nasopharyngeal and lung epithelial cells and elicits functional antibodies in humans. Microbes Infect 14: 1102-1110, 2012. 